\title{
A Low-Cost PC-Based Range Finder System
}

\author{
S. M. A. Motakabber and Muhammad I. Ibrahimy
}

\begin{abstract}
Now computerization is the most popular, reliable and flexible design for various types of control and communication systems. Sound navigation and ranging (SONAR) is a modern ultrasonic range finding technique used for collecting the information about a distant object without any physical contact. In this research work a PC based active SONAR system is proposed. A pair of $40 \mathrm{kHz}$ piezoelectric ultrasonic transducers is used in this project. A driver-software named is developed using turbo $C$ language aimed at IBM PC and its clone machines. The software provides necessary support for interfacing the hardware as well as calculations. A numbers of test were done and found that the proposed system performances are good in terms of accuracy $\pm 5 \%$, simplicity, cost and power consumption.
\end{abstract}

Index Terms - SONAR, under water radar, ultrasonic range finder, ultrasound, computer interfacing, piezoelectric transducer.

\section{INTRODUCTION}

Due to simplicity and low-cost interfacing hardware many data acquisition through the parallel port have been built in the past [1]-[4]. However, either those works have not been reported comprehensively or there have been too many complexities in the approached development which may hard to realize. This paper is to report a complete working system with less complexity computer aided active sonar system. The word sonar is an American term first used in World War II; it is an acronym for Sound, Navigation and Ranging [5]. Sonar uses sound wave to find the range and to detect the objects. It uses $30 \mathrm{~Hz}-300 \mathrm{kHz}$ low frequency band (LFB) or $300 \mathrm{kHz}-3000 \mathrm{kHz}$ high frequency band (HFB) sound wave to locate an object. There are different types of ultrasonic range finder according to the applications [6][7] and these are sometimes very complex in circuitry due to high precision. A simple block diagram of the proposed system is shown in Fig. 1 .

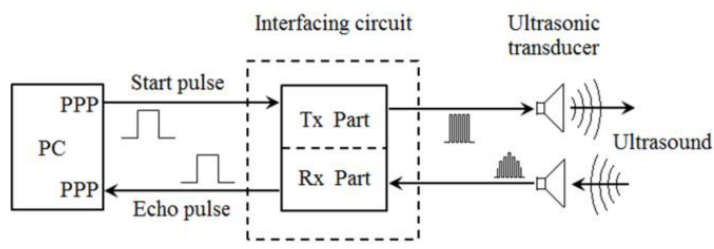

Fig. 1. Simple block diagram of a computer aided active sonar system.

The PC controls the overall functions of the system as well as supporting the required interfacing and calculations. At the

Manuscript received May 20, 2013; revised May 28, 2013. This research is supported by the Ministry of Higher Education, Malaysia.

The authors are with the International Islamic University Malaysia, $53100 \quad$ KL, Malaysia (e-mail: amotakabber@iium.edu.my, ibrahimy@iium.edu.my). beginning, PC sends a start bit through the pin 2 (D0) of the parallel printer port (Fig. 2) to command the control circuit to work as a transmitter unit. When the control circuit would receive a start bit, it enables an electronic oscillator to generate $40 \mathrm{kHz}$ frequency for the ultrasonic transducer. The on and off conditions of the oscillator depends on the control signal of the PC. The transmitting transducer converts the electrical signal into a sound wave and transmits toward the target through a parabolic sound reflector into the air. The receiving transducer converts the received echo sound into an equivalent electrical signal. A comparator circuit compares the received signal with a reference voltage and allows the desired signal to control an SR flip-flop. The time difference between the rising edge of the transmit signal and rising edge of the receive signal can be found from the interval state of the SR flip-flop.

Ones the output of the flip-flop is set to logic ' 1 ' its value would remain logic ' 1 ' until it would receive a reset signal from the comparator. The LPT parallel printer port of the PC is programmed as a bidirectional mode of operation by setting the control bit C5 equal to logic ' 1 '. The output of the SR flip-flop is connected to the pin 3 (D1) of the D-connector of the LPT parallel printer port as an input data bit. The exact start time of the transmitted signal is stored in the PC and at the same time the start signal (D0) would be triggered both the oscillator as well as the set pin of the flip-flop. Similarly, the exact time of the received signal can also be stored in the PC (D1) when the echo signal would appear on the reset pin of the flip-flop. The round trip time of the ultrasound is the difference of these two times.

\begin{tabular}{ccc}
\multicolumn{3}{c}{ TABLE I: SOME OBSERVED DATA } \\
\hline \hline Observation & $\begin{array}{c}\text { Actual distance } \\
(\mathrm{m})\end{array}$ & $\begin{array}{c}\text { Measured } \\
\text { distance }(\mathrm{m})\end{array}$ \\
\hline 1 & 0.3 & 0.25 \\
2 & 0.6 & 0.51 \\
3 & 1.2 & 1.08 \\
4 & 1.8 & 1.71 \\
5 & 2.4 & 2.46 \\
6 & 3.6 & 3.69 \\
7 & 4.2 & 4.35 \\
8 & 4.8 & 4.95 \\
9 & 5.4 & 5.58 \\
10 & 6 & 6.24 \\
\hline \hline
\end{tabular}

\section{PARALlEL PORT INTERFACING}

The LPT parallel printer port is the most commonly used interfacing port for a simple to moderate projects of the researchers. The LPT parallel port was originally developed by IBM [8], as a way to connect a line printer to the PC. The port is composed with 4 control lines, 5 status lines and 8 data lines. These are found commonly on the backside of the PC as a D-type 25 pin female connector as shown in Fig. 2. The 
base address of the port is usually called the data port or data register and is simply used for outputting the data through the data lines (pins 2-9) of the parallel port. In this project data bit D0 (pin 2) is used for signal out from the PC. The status register (base address +1 ) is a read only port. The status port is composed with 5 input lines pins $10,11,12,13$ and 15 ( $\hat{\mathrm{S}} 7$, S6, S5, S4 and S3), an interrupt request (IRQ) status bit and two reserved bits respectively. Finally, the control register (base address +2) is a programmable read/write register, which data bit S5 can be programed to use the parallel printer port as a unidirectional or a bi-directional mode of operation.

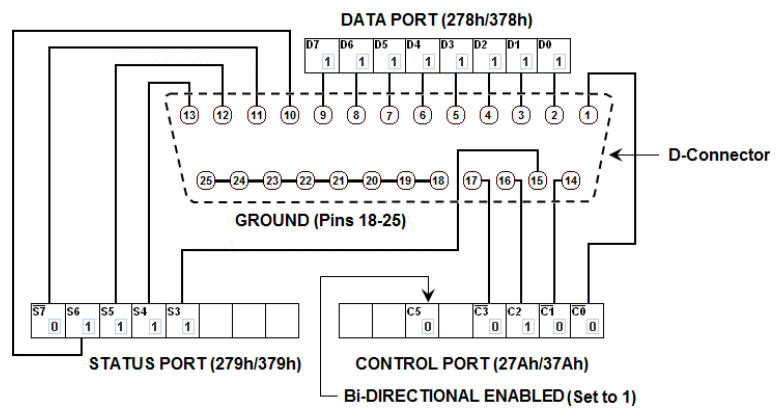

Fig. 2. Standard LPT parallel printer port D-connector's pin connection and its signals [8].

\section{RANGE CALCULATION}

The distance of the target from the transducers can be calculated by using the following equations.

$$
S=v t / 2
$$

Where, $v$ is the speed of sound meter/sec in air and $t$ is the total round trip time in second.

If it assumes that air as an ideal gas the speed of sound $v$ can be calculated by Equation 2

$$
v=\sqrt{\delta R T}
$$

where constants, $\delta=1.4, R=287 \mathrm{~m}^{2} /\left(\mathrm{s}^{2}-\mathrm{K}\right)$ and the $T$ is the absolute temperature in Kelvin. Using these constant values the approximate velocity can be calculated by Equation 3

$$
v \cong 20 \sqrt{T}
$$

Combining Equations 1 and 2, the distance can be represented by Equation 5

$$
S=10 \sqrt{T t}
$$

\section{INTERFACING ALGORITHM}

The algorithm of the interfacing software is as bellows.

// $T_{S}=$ star time, $T_{E}=$ end time, $T_{D}=$ time difference and $S=$ distance in $m$

1) Set, $T_{D}=0, S=0$

2) Output, $D O=1$ hex (through port 278 hex for a start the oscillator and set the $\mathrm{f} / \mathrm{f}$ )

3) Set, $T_{S}=$ time of the PC system clock

4) Output, $C_{S}=1$ hex (through port $27 \mathrm{~A}$ hex, to set the data port as input port)

5) Input $I=D 1$ (through port $378 \mathrm{hex}$ )
6) If $(I=0)$ then go to step 3 otherwise go to step 7

7) Set, $T_{E}=$ time of the PC system clock

8) $T_{D}=T_{E}-T_{S}$

9) Input, $C=$ surrounding temperature in Celsius

10) $V_{s}=20 \sqrt{273.6+C}$

11) $S=V_{S} \times \frac{T_{D}}{2}$

12) Print $S, T_{S}, T_{D}$

13) Exit from program

\section{RESUlT AND DISCUSSION}

The developed system obeys with the theoretical calculations and obtained a satisfactory experimental result. A variety of obstacle materials are used in this research such as, concrete wall, vinyl board, paper books, cloth bag etc. and found that the result is almost same. Some of the observed data and its graphical representation are shown in Table 1 and Fig. 3 respectively.

The overall experiments are done under laboratory control environment by placing the transmitting and receiving transducers inside of two separate large parabolic sound reflectors. The experiment was limited between the ranges $0.3 \mathrm{~m}$ to $6.0 \mathrm{~m}$ due to the constraint of transducer output power and the receiver sensitivity. An electronic temperature sensor was used to measure the ambient temperature to calculate the velocity of the sound in the air. From Fig. 3 it is found that the system has the best performance between $1.5 \mathrm{~m}$ to $2.5 \mathrm{~m}$ ranges. The overall performance of the system ranges between $0.3 \mathrm{~m}$ to $6.0 \mathrm{~m}$ is tested and observed $\pm 5 \%$ errors.

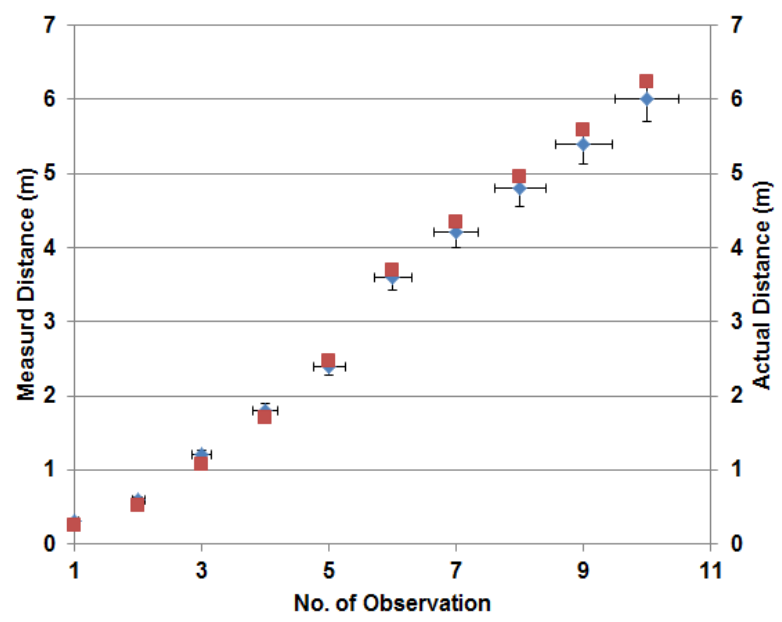

Fig. 3. Measured and actual distances with 5\% error scale.

The overall experiments are done under laboratory control environment by placing the transmitting and receiving transducers inside of two separate large parabolic sound reflectors. The experiment was limited between the ranges $0.3 \mathrm{~m}$ to $6.0 \mathrm{~m}$ due to the constraint of transducer output power and the receiver sensitivity. An electronic temperature sensor was used to measure the ambient temperature to calculate the velocity of the sound in the air. From Fig. 3 it is found that the system has the best performance between $1.5 \mathrm{~m}$ to $2.5 \mathrm{~m}$ ranges. The overall performance of the system ranges between $0.3 \mathrm{~m}$ to $6.0 \mathrm{~m}$ is tested and observed $\pm 5 \%$ errors. 


\section{CONCLUSION}

A simple low-cost steady state platform was designed and constructed for investigation purpose. The uncertainty of the maximum distance measured is mostly depending on the target's physical geometry, texture and its orientation. The main attraction of this research is a static PC based active sonar range finder system with low-cost, easy to implement and inherently safe to use. However, a sophisticated algorithm and advanced control techniques can be investigated to develop a high efficient system which can be applied to a dynamic sonar system.

\section{REFERENCES}

[1] Standard signaling method for bidirectional parallel peripheral interface for personal computers, IEEE Standard, pp. 1284-1994, 1994.

[2] M. Rodriguez, A. Ayala, F. Rosa, F. Herrera, S. Rodriguez, M. D. Gonzalez and S. R. Buenafuente, "A low-cost interface circuit to enable A/D conversion using the parallel port," Int. J. Electr. Eng. Educ., vol. 38, no. 3, pp. 222-231, 2001.

[3] P. H. Anderson. (2012). Use of a PC printer Port for control and data acquisition. [Online]. Available: http://et.nmsu.edu/ etti/fall96/computer/printer/printer.html

[4] J. Axelon, "Parallel port complete: programming, interfacing and using the PC's parallel printer port," Lakeview Research (USA), 2000.

[5] T. Devereux, Messenger gods of battle: radio, radar, sonar, the story of electronics in war, UK: Brassey's, 1991.

[6] A. Carullo and M. Parvis, "An ultrasonic sensor for distance measurement in automotive applications," IEEE Sensors Journal, vol. 1, no. 2, pp. 143-147, 2001

[7] M. S. Young and Y. C. Li, "A high precision ultrasonic system for vibration measurements," Rev. Sci. Instrum, vol. 63, no. 11, pp. 5435-5441, 1992.

[8] C. Bhunia, S. Giri, S. Kar, S. Haldar, and P. Purkait, "A low-cost PC-based virtual oscilloscope," IEEE Transactions on Education, vol. 47, no. 2, pp. 295-299, May 2004.

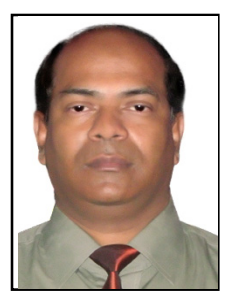

S. M. A. Motakabber was born in Naogaon, Bangladesh, in May 1966. He received the B.Sc. and M.Sc. degrees in applied physics and electronics from the University of Rajshahi, Bangladesh, in 1986 and 1987, respectively, and the Ph.D. degree in electrical, electronic and systems engineering from the National University of Malaysia, in 2011. From 1993 to 2011, he was a Associate Professor in the Department of Applied Physics and Electronic Engineering at the University of Rajshahi, Bangladesh. He is now Assistant Professor in the Department of Electrical and Computer Engineering at the International Islamic University of Malaysia. Dr. Motakabber is a member of the Institute of Electrical and Electronics Engineers (IEEE), a life member of the Bangladesh Association for Advancement of Science (BAAS) and the Bangladesh Electronics Society (BEC). His research interests are Analog \& Digital Electronic System Design, Medical \& Industrial Instrumentation, VLSI Design, RFID, Robotics, Automation and Computer Control Systems. He has published about 20 research articles in peer reviewed journals, conferences and 1 book.

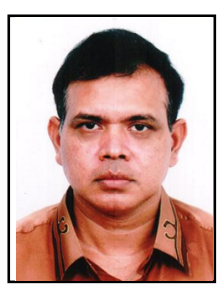

Muhammad I. Ibrahimy was born in Sirajgonj, Bangladesh, in August 1962. He received the B.Sc. and M.Sc. degrees in applied physics and electronics from the University of Rajshahi, Bangladesh, in 1985 and 1986, respectively, and the $\mathrm{Ph} . \mathrm{D}$. degree in biomedical signal processing from the National University of Malaysia, in 2001. From 2001 to 2003, he was a Postdoctoral Fellow in the Department of Electrical and Electronic Engineering at the Mie University of Japan. He is now Associate Professor in the Department of Electrical and Computer Engineering at the International Islamic University of Malaysia. Dr. Ibrahimy is a member of the Institute of Electrical and Electronics Engineers (IEEE), a member of the Bangladesh Computer Society (BCS) and the Bangladesh Electronics Society (BEC). His research interests are Analog \& Digital Electronic System Design, Medical \& Industrial Instrumentation, Biomedical Signal Processing, VLSI Design, RFID and Computer Networks in Telemedicine. He has published about 50 research articles in peer reviewed journals, conferences and 2 books. 